INTERNATIONAL HIGHER EDUCATION - NUMBER 68 SUMMER 2012 Pages 17-18.

\title{
Serbia: New Higher Education Strategy
}

\author{
STAMENKA UVALIĆ-TRUMBIĆ
}

Stamenka Uvalić-Trumbić is an independent consultant in global higher education. She was formerly chief of the Higher Education Section at the United Nations Educational, Scientific, and Cultural Organization. E-mail: suvalictrumbic@gmail.com.

In Serbia a new higher education strategy, as a wider reform, treats education from preschool to doctoral studies in a holistic manner. European Union documents and targets provide the overall inspiration for the strategy, notably the Europe 2020 objectives of growth for which education and training are vital.

However, higher education in Serbia inherits a challenging legacy. It was originally part of a wider Yugoslav higher education context but has since suffered years of civil war, political instability, and economic sanctions.

\section{BOOSTING ENROLLMENT}

Serbia's principal challenge is to raise its gross enrollment rate, currently only 26.6 percent, toward the European average of 50 to 55 percent-and to move to this level without producing too many graduates or lowering standards. Demographic trends partly account for low, and declining, enrollments; but high-graduate unemployment, a by-product of the poor economic situation, is a more immediate cause. Also a steady 
and massive brain drain has occurred over the past 20 years, which has been more extensive in Serbia than elsewhere in the western Balkans. Designing higher education curricula that are more closely aligned to labor-market requirements will go some way to address this problem. Recruiting new researchers is another crucial issue, given the European target of creating at least 1 million new research jobs, in order to reach a research and development target of 3 percent of gross domestic product.

\section{Legacy of the Past: Overcoming Fragmentation}

A particular challenge for higher education in Serbia-a historic legacy of all former Yugoslav republics-is the tradition that universities are groupings of semiautonomous faculties rather than fully integrated institutions. Integrated corporate structures are essential for any sustainable reforms, yet 20 years of debate have not resolved this question in major universities, such as Belgrade, although some smaller institutions have made progress.

Furthermore, recent proliferation of higher education institutions further fragments the subsector and works against coherent planning. Before Yugoslavia disintegrated, Serbia had four universities, in Serbia proper, and another two in its autonomous provinces, Vojvodina and Kosovo. Today, the draft strategy mentions 13 accredited universities ( 7 public and 6 private) for a population that is now smaller than in those earlier days—and still declining.

A critical issue is to reduce the number of separate public universities, to achieve a more rational network of institutions-matching the needs of the country. 


\section{Serbia AND European Processes}

Since 2003, Serbia has participated well in European initiatives—such as, the European Higher Education Area and later the European Research Area. This has ensured the gradual evolution of degree structures, the development of national qualifications frameworks based on learning outcomes, the establishment of quality-assurance mechanisms, and the inclusion of key stakeholders-i.e., students, in decision-making processes. Unfortunately, however, there is no critical analysis of the implementation of the Bologna process-acknowledging, perhaps, that some changes may have been merely cosmetic. For example, changing the degree framework without reforming study programs has put both students and faculty under pressure. In addition, the value of the bachelor's degree has been diminished, as it no longer provides access to the labor market, and also of the master's degree, which has lost its research component.

\section{DiverSIFICATION}

To diversify the higher education sector, the 2005 Higher Education Act introduced a binary system with four-year professional studies, although it did not provide movement between the university and nonuniversity sectors. The major reform needed now is to amend the legislation covering the nonuniversity tertiary sector, to promote greater vertical and horizontal mobility. Serbia's current arrangements are inconsistent with the practice of vertical and horizontal movement of students found elsewhere in Europe. 
At the other end of the spectrum, in its quest for excellence, the strategy aspires to develop competency indicators for higher education institutions at the national level and also to introduce policies to help a few Serbian universities rate highly in major international university rankings and achieve top spots in regional rankings.

High positions in international and/or regional rankings boost national pride, and Serbian higher education institutions undoubtedly achieve excellence in some disciplines. Research shows that three conditions for securing high positions in international league tables constitute strong leadership, purposeful governance structures, and substantial investment of resources. However, the necessary resources seems unavailable in Serbia; and even if they were, they might be better deployed in developing a quality higher education system for Serbia, as a whole-instead of boosting a few select institutions without a guarantee of success.

\section{ACADEMIC CORRUPTION}

Faced with a major case of academic corruption, resulting in legal repercussions and resignations of faculty deans in 2007, the strategy proposes a Code of Ethics at the institutional level for all universities. To have real impact, it seems that such a code could be reinforced as an element of quality assurance and accreditation and be monitored regularly.

\section{TURNING WEAKNESSES INTO STRENGTHS}

Serbia should seek to turn its weaknesses into strengths. For example, incentives could be created for the universities to include Serbia's impressive intellectual diaspora in 
their teaching and research, through visiting professors positions and joint research projects. Now that memories of civil war are receding, Serbia should also exploit the common linguistic heritage of the western Balkans to develop joint doctoral studies with other countries of the region. Creating regional disciplinary networks with poles of excellence in Serbia and throughout the Yugo-sphere might be a mechanism for reducing the number of universities, increasing quality, and reinforcing the relevance of study programs.

\section{CONCLUSION}

Will this new strategy, though a well-researched and thorough document, just be one of many that have never been implemented, a political asset in function of the upcoming elections in Serbia? Unless it is integrated with overall policies in other sectors and is an integral part of Serbia's wider Strategy for Economic Development (for the decade to 2020), it is likely to remain an isolated document-with little chances for the muchneeded improvements of the higher education system. 